\title{
Biomimetic Apatite Layer on Titanium by Diluted Alkali Treatment
}

\author{
Wenjun $\mathrm{He}^{1,2, \mathrm{a}}$, Ruifu Zhu ${ }^{1, \mathrm{~b}}$ and Yupeng Lü ${ }^{1, \mathrm{c}}$ \\ ${ }^{1}$ College of Materials Science and Technology, Shandong University of China, Jinan 250061, China \\ ${ }^{2}$ Shandong Key Laboratory of Metrology and Measurement, Shandong Institute of Metrology, Jinan \\ 250014, China

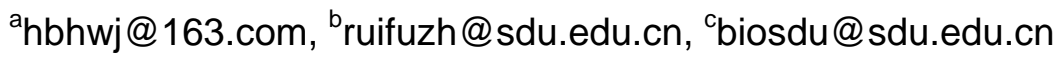

Keywords: Titanium; Hydroxyapatite; Bioactivity; Diluted Alkali Treatment.

\begin{abstract}
The bioactivity of titanium treated with boiling diluted alkali process was evaluated by immersing the specimens into a supersaturated calcification solution (SCS). Biomimetic bone-like apatite with typical characteristics of low crystallinity and lower $\mathrm{Ca} / \mathrm{P}$ atomic ratio ranging from 1.33 to 1.45 was deposited on titanium surface. Uniform and dense needle-like apatite in the size of several microns was deposited by boiling diluted alkali treatment but without acid etching and heat treatment. The critical and imperative factor to activate the nucleation and growth of apatite is the boiling diluted alkali treatment other than acid etching or heat treatment. The nucleation and growth of the apatite deposited on titanium surface can be attributed to the amphoteric adsorption characteristics and negatively-charged surface of titanium oxides or titania gel.
\end{abstract}

\section{Introduction}

Titanium and titanium alloys are very attractive implant biomaterials due to high biocorrosion resistance, biocompatibility and mechanical properties [1]. Despite these excellent properties, titanium and its alloys are considered to be bioinert and not likely to form a chemical bond with bone after implanting. However, apatite coatings such as hydroxyapatite $\left(\mathrm{Ca}_{10}\left(\mathrm{PO}_{4}\right)_{6} \mathrm{OH}, \mathrm{HA}\right)$ coated on titanium surface are well recognized to have led to better long-term clinical success rates than uncoated titanium implants [2].

Several methods have been developed to coat apatite layer on the surface of titanium implants such as sol-gel coating, electrophoretic deposition, plasma spraying and biomimetic precipitation [3]. The most promising techniques for producing apatite layer is the biomimetic method, which mimics the mineralization process of bone by utilizing the supersaturated aqueous solutions with ionic composition similar to that of human plasma. Prior to the biomimetic precipitation of apatite layer, an important requirement for titanium implants is the bioactive surface developed by chemical treatments such as alkali-, heat-, or $\mathrm{H}_{2} \mathrm{O}_{2}$-treated processes [4]. Alkali-treated methods consist of highly concentrated alkali treatment and boiling diluted alkali incubation. The alkali solution of the former is mainly $1 \sim 10 \mathrm{M} \mathrm{NaOH}$ or $\mathrm{KOH}$. The latter is a simple and effective means to bioactivate titanium surface without requirements of acid etching or mechanical polishing, which is very suitable for the complex-shaped titanium implants.

Currently, the research about the bioactive effect of alkali-treated method focuses mainly on that of high-concentration alkali and/or heat treatment, and little on that of diluted alkali. Moreover, the effect of acid etching before or heat treatment after diluted alkali treatment on the bioactivity of titanium is not clear. In the present study, the formation of apatite layer on titanium surface by different diluted alkali treatment has been investigated after immersion in SCS solution.

\section{Experimental}

Commercially pure titanium rods $(\Phi 13 \mathrm{~mm} \times 10 \mathrm{~mm})$ were used as substrates. Their surfaces were ground and cleaned ultrasonically in acetone and 70\% ethanol for $20 \mathrm{~min}$, respectively, rinsed in distilled water, and finally dried at 40C. Before immersion in boiling $0.2 \mathrm{M} \mathrm{NaOH}$ solution at $140^{\circ} \mathrm{C}$ for $5 \mathrm{~h}$ in a pressure canner, some specimens were acid-etching for $30 \mathrm{~min}$ with a solution 
containing $\mathrm{HCl}(18 \mathrm{wt} \%)$ and $\mathrm{H}_{2} \mathrm{SO}_{4}(48 \mathrm{wt} \%)$. After boiling diluted alkali treatment, heat process can be carried out on the treated titanium specimen at 500C for $1 \mathrm{~h}$. To increase the bioactivity of titanium surface, the treated specimens were precalcified (pre-Ca) by soaking in $0.5 \mathrm{~N}$ $\mathrm{Na}_{2} \mathrm{HPO}_{4} \cdot 2 \mathrm{H}_{2} \mathrm{O}$ at $40 \mathrm{C}$ for $24 \mathrm{~h}$ and then in saturated $\mathrm{Ca}(\mathrm{OH})_{2}$ solution at $60 \mathrm{C}$ for $5 \mathrm{~h}$. The in vitro SCS for immersion experiments was prepared as described in the literature [5]. The final inorganic ion concentration [in $\mathrm{mM}$ ] was $136.8 \mathrm{Na}^{+}, 4.64 \mathrm{~K}^{+}, 3.10 \mathrm{Ca}^{2+}, 144.5 \mathrm{Cl}^{-}$, and $1.86 \mathrm{HPO}_{4}{ }^{2-}$. After immersing in SCS, the specimens were gently washed with distilled water and dried at 60C. SCS solution changes once every 3 days and keeps constant temperature of 36.5C. The Specimen surfaces were examined by scanning electron microscopy (SEM) and X-ray diffractometry (XRD). XRD patterns were recorded with a Rigaku D/Max-rB diffractometer using CuKa radiation. SEM photographs were taken using a JXA-840 microscope with the EDAX 9100 spectrometer.

\section{Apatite Deposition Observation}

Table 1 shows the deposition effect of apatite layer on titanium surface for specimens ( $\mathbb{\nabla} \tilde{)}$ treated with different processes by direct observation and XRD analysis. The apatite layer was deposited on each titanium specimen treated by boiling diluted alkali, whether the specimen was additionally treated by acid etching, heat treatment, pre-Ca process or not. It shows that the boiling diluted alkali treatment takes a critical role in the deposition of apatite layer after immersion at SCS or the bio-activation of titanium surface, which was agreement with the previous report [5] that the titanium surface was bio-activated only as the concentration of the boiling diluted alkali is above a definite value. Acid etching was considered to develop the micro-porous structure of titanium surface, promoting the nucleation of apatite. The utilization of pre-Ca was reported to accelerate the deposition of apatite layer remarkably. In the present study, we found that the deposition effect of apatite layer is not influenced remarkably by the acid etching or pre-Ca process.

Table 1 Deposition Effect of apatite layer by different diluted alkali treatments

\begin{tabular}{ccccccc}
\hline Specimens & $\begin{array}{c}\text { Acid } \\
\text { etching }\end{array}$ & $\begin{array}{c}\text { diluted alkali } \\
\text { treatments }\end{array}$ & $\begin{array}{c}\text { Heat } \\
\text { treatment }\end{array}$ & Pre-Ca & $\begin{array}{c}\text { Immersion } \\
\text { time (d) }\end{array}$ & $\begin{array}{c}\text { Deposition effect } \\
\text { of apatite layer }\end{array}$ \\
\hline I & $\mathrm{N}$ & $\mathrm{Y}$ & $\mathrm{N}$ & $\mathrm{Y}$ & 8 & Y, good \\
II & $\mathrm{N}$ & $\mathrm{Y}$ & $\mathrm{N}$ & $\mathrm{Y}$ & 18 & Y, good \\
III & $\mathrm{Y}$ & $\mathrm{Y}$ & $\mathrm{Y}$ & $\mathrm{N}$ & 12 & $\mathrm{Y}$ \\
IV & $\mathrm{Y}$ & $\mathrm{Y}$ & $\mathrm{Y}$ & $\mathrm{Y}$ & 8 & $\mathrm{Y}$ \\
$\mathrm{V}$ & $\mathrm{Y}$ & $\mathrm{Y}$ & $\mathrm{Y}$ & $\mathrm{Y}$ & 14 & $\mathrm{Y}$ \\
\hline
\end{tabular}

*Y-Yes; N-No.

\section{Analysis of apatite layer deposited}

Fig. 1 shows XRD patterns of apatite layer deposited on the specimens ( $\mathbb{I}$ and IV) from SCS. By comparing with the standard cards of JCPDS [6], two typical peaks at $2 \theta \approx 26^{\circ}$ and $32^{\circ}$ of HA with similar XRD patterns were seen for two specimens( I and II ) treated without acid etching and heat treatment (Fig. 1a and Fig. 1b). However, the pattern of specimen tweated with acid etching and heat treatment did not show a typical HA peaks at $2 \theta \approx 26^{\circ}$, although a relative weak peak at $2 \theta$ $\approx 32^{\circ}$ was seen as shown in Fig. 1c. The relative weak peak and the existence of broad peaks indicated that the deposition HA layer is composed of crystalline apatite with low crystallinity and amorphous apatite. Thus, the HA layer has typical characteristics of bone-like apatite with low crystallinity and imperfect structure. The difference of XRD patterns between the specimens ( I and II ) and specimen IV indicated that acid etching before diluted alkali treatment and heat treatment after diluted alkali treatment are not essential requirements for bio-activation of titanium. Meanwhile, XRD patterns of three specimens did not show the apparent typical peak of $\mathrm{TiO}_{2}$ crystal. Without the process of acid etching or heat treatment, the increase in the crystallinity of 
apatite layer and the still existence of broad peak indicated that the growth of apatite is limited after the end of the immersion test in SCS.

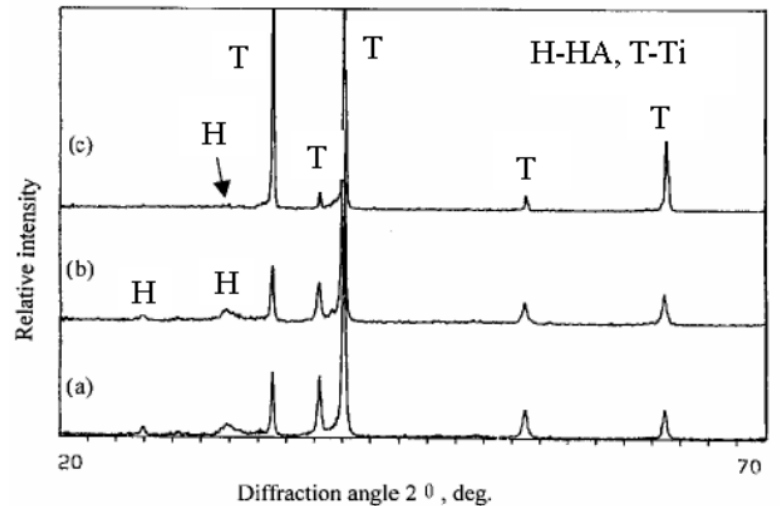

Fig. 1 XRD patterns for HA layer on the surfaces of titanium specimen (a)

boiling diluted alkali treatments (H: HA, T: Ti)

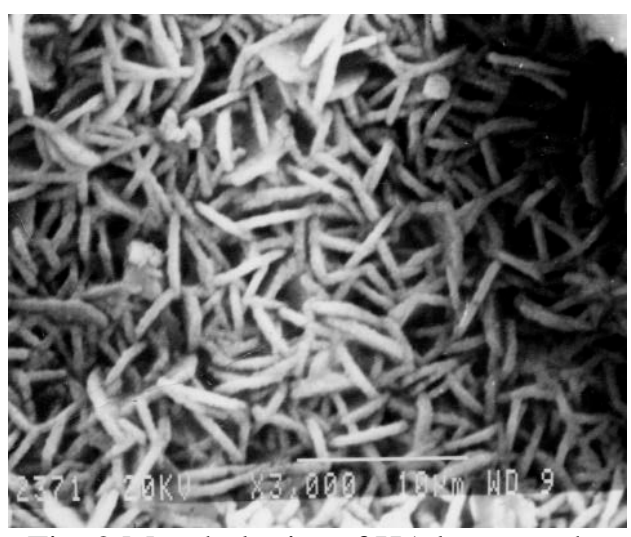

Fig. 2 Morphologies of HA layer on the

I , (b) II and (csulfflase diffserenitmen I $(\times 3000)$

Fig. 2 is the morphology of HA layer on the titanium surface (specimen I ). Only for 8 days immersion in SCS, titanium surface appears a dense and uniform well-crystallized HA layer with needle-like or rod-shaped crystal. The needle-like apatite crystals overlapped disorderly each other without preferential growth orientation. The crystals have almost the same size with the diameter of about $1 \mu \mathrm{m}$ and the length of about $5 \mu \mathrm{m}$. The morphology of apatite layer shows a different characteristic from that deposited by the alkali- and subsequent heat treatment [4]. The difference was attributed to that the specimen treated by boiling diluted alkali in a pressure container possesses a larger internal stress with an unstable state of high energy. Once the specimen with an unstable state immersing into SCS, it tends to gain the imperative energy and degree of supersaturation which are the essential requirements to favor apatite nucleation with the motivation of higher concentration of calcium ions and phosphate ions.

Fig. 3 shows the morphology of HA layer on the titanium surface (specimen II). After 18 days immersion in SCS, a dense but nonuniform apatite layer was formed on titanium surface. Table 2 shows the result of element compositions at various points in Fig. 3. $\mathrm{Ca} / \mathrm{P}$ atomic ratio of all three point (A, B and C) ranges from 1.45 to 1.33, which was consistent with the previous research [5] that $\mathrm{Ca} / \mathrm{P}$ atomic ratio of bone-like apatite deposited by bioactive chemical treatment ranges from 1.34 to 1.58 . The present value of $\mathrm{Ca} / \mathrm{P}$ atomic ratio is much lower than that of stoichiometric $\mathrm{HA}$ with a value of 1.67. Compared with the specimen I, the increase in the immersion time in SCS leads to the aggregation of apatite crystal into a dense but nonuiniform apatite layer. The decrease of $\mathrm{Ca} / \mathrm{P}$ atomic ratio was attributed to the precipitation of non-HA calcium phosphate phase such as $\mathrm{Ca}_{8} \mathrm{H}_{2}\left(\mathrm{PO}_{4}\right)_{6} \cdot 5 \mathrm{H}_{2} \mathrm{O}$ with $\mathrm{Ca} / \mathrm{P}$ atomic ratio of 1.33 [7].

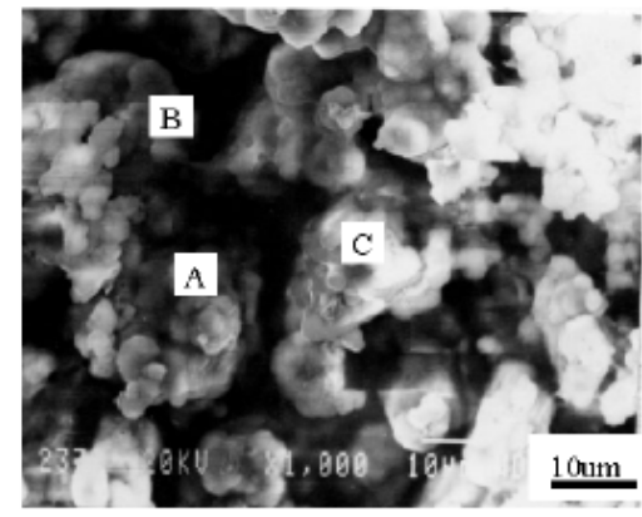

Fig. 3 Morphology of HA layer on the surface of specimen II

Table 2 Compositions of point $\mathrm{A}, \mathrm{B}$ and $\mathrm{C}$ in Fig. 3

\begin{tabular}{ccccccc}
\hline \multirow{2}{*}{ Element } & \multicolumn{2}{c}{ Point A } & \multicolumn{2}{c}{ Point B } & \multicolumn{2}{c}{ Point C } \\
& wt.\% & at.\% & wt.\% & at.\% & wt.\% & at.\% \\
\hline $\mathrm{Ca}$ & 37.78 & 22.42 & 35.59 & 20.77 & 35.27 & 20.53 \\
$\mathrm{P}$ & 20.10 & 15.43 & 20.58 & 15.55 & 20.28 & 15.27 \\
$\mathrm{Ti}$ & 0.41 & 0.20 & 0.41 & 0.20 & 0.62 & 0.30 \\
$\mathrm{Ca} / \mathrm{P}$ & & & & & & \\
(at.\%) & 1.45 & 1.33 & 1.34 \\
\hline
\end{tabular}

Fig. 4 shows the morphology of HA layer deposited on the titanium surface (specimen I ) with 
the addition of acid etching, heat treatment and pre-Ca process. As shown in Fig. 4a, a large number of cracks and holes appear on the titanium surface after acid etching. The hole is $2 \sim 5 \mu \mathrm{m}$ in diameter and its distributions were disorganized without preferential orientation. Apatite layer with white floc-like shape was irregularly deposited on the titanium surface with inhomogeneous distribution, though nearly no apatite layer was deposited in some areas or locations. Fig. $4 \mathrm{~b}$ is the enlargement of area A (Fig. 4a) at 5000× magnification. The size and shape of the hole in the HA layer was clearly found after its deposition on the acid-etching surface, indicating that the deposited HA layer does not fully cover the acid-etching surface and the apatite crystals nucleate along the inwall of the surface hole and grow vertically.

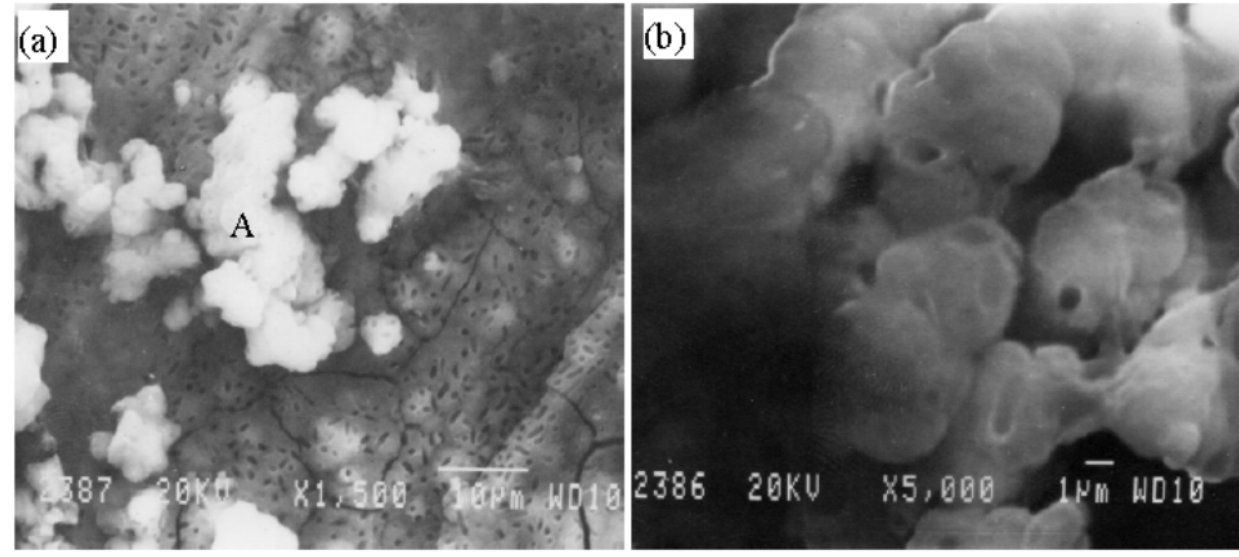

Fig. 4 Morphologies of HA layer on the surface of specimen $\mathrm{V}$

(a) $\times 1500$, (b) enlargement morphology of area A $(\times 5000)$

\section{Mechanism of Apatite Nucleation and Growth}

In natural mineralization system, the nano-scale space with the distribution of special negative charges on the organic matrix has an important significance in the nucleation of bone apatite. The nano-interstice is the most preferential position for the nucleation and growth of apatite microcrystal. Similarly, the deposition substance negatively charged on the surface of porous metal material is likely to be an effective means to precipitate apatite in SCS. The special microstructure of the titanium surface via chemical treatment with submicron scale may be another important factor to favour the apatite nucleation [5, 7].

The titanium surface via boiling dilute alkali treatment has the typical characteristics such as the formation of surface hole with sub-micron structure and the titanium oxide (generally for $\mathrm{TiO}_{2}$ ) layer that was negatively charged in aqueous solution. The typical structure characteristics are similar to the essential requirements for the formation of bone apatite. Thus the modification of titanium surface favours the rapid deposition of apatite layer in the SCS solution. In the present study, the titanium surface treated by acid etching and subsequent boiling diluted alkali shows the typical submicron porous structure with lots of holes and cracks as shown in Fig. 4a. From Fig. 4b, the hypothesis that porous structure is favorable for the nucleation and growth of apatite was partly supported. However, the fact that no apatite layer was deposited in some locations of titanium surface (specimens V) even with lots of holes and cracks (Fig. 4a) indicated that the effect of porous structure on favoring the nucleation and growth of apatite layer is questionable and not positive. That is to say, the acid etching before boiling diluted alkali treatment on titanium is not necessarily a positive and indispensable process.

The titanium surface treated by acid etching, boiling diluted alkali treatment or heat treatment was employed to form titanium oxides or titania gel. The titanium oxides including $\mathrm{TiO}_{2}$ type of rutile and anatase or titania gel exhibit amphoteric characteristic of hydroxyl phenomenon as their surface was adsorbed with the water or water vapor, leading to the formation of acid hydroxyl $\mathrm{OH}$ (s) and alkaline hydroxy Ti-OH simultaneously. A single hydroxyl group cooperates with $\mathrm{Ti}^{4+}$ into alkaline hydroxyl, while two hydroxyl groups cooperate with $\mathrm{Ti}^{4+}$ into acid hydroxy [8]. Thus the surface of titanium oxides can adsorb either cation ion or anions. It can also be negatively charged 
in the solution with $\mathrm{pH}$ from 7.2 to 7.4 [9]. The titanium oxides adsorb $\mathrm{HPO}_{4}{ }^{2-}$ or $\mathrm{Ca}^{2+}$ in SCS leading to local Ca-P supersaturation. The local Ca-P supersaturation and the negative charged titania gel are two important factors to favour the nucleation of apatite in SCS. After nucleation of apatite, the growth is controlled just by the consumptions of $\mathrm{Ca}^{2+}$ and $\mathrm{PO}_{4}{ }^{3-}$ in SCS but not by the ion diffusion of the solution. From the above XRD analysis, the deposited apatite is initially amorphous and then crystallized with the immersion time in SCS. Compared with stoichiometric $\mathrm{HA}$, the titania surface adsorbs $\mathrm{HPO}_{4}{ }^{2-}$ more than $\mathrm{Ca}^{2+}$ in SCS, leading to the deposition of bone-like apatite with lower $\mathrm{Ca} / \mathrm{P}$ atomic ratio (Table 2). From the deposition of apatite layer on titanium (specimen I and V), it is noted that boiling diluted alkali treatment is the critical factor to activate the nucleation and growth of apatite other than acid etching or heat treatment.

\section{Conclusion}

Bone-like apatite with low crystallinity and lower $\mathrm{Ca} / \mathrm{P}$ atomic ratio ranging from 1.33 to 1.45 was deposited on titanium surface treated by boiling diluted alkali solution via a biomimetic immersion in SCS. The critical factor to activate the nucleation and growth of apatite is the boiling diluted alkali treatment other than acid etching or heat treatment. The specimens treated by boiling diluted alkali but without acid etching and heat treatment shows uniform and dense needle-like apatite with the size of several-micro scale. The apatite deposited on titanium surface can be attributed to the amphoteric adsorption characteristics and the negatively-charged surface of titanium oxides or titania gel. Boiling dilute alkali treatment has several advantages of lower temperature, low alkali concentration and without the requirements of acid etching, being less damaged to the titanium substrate and beneficial to the clinical application of titanium implants.

\section{References}

[1] Niinomi M. Mechanical properties of biomedical titanium alloys. Mater Sci Eng A, 1998, 243 : 231-236.

[2] Kokubo T, Yamaguchi S. Bioactive Ti metal and its alloys prepared by chemical treatments: state-of-the-art and future trends. Adv Eng Mater, 2010, 22: B579-B591.

[3] Barrère F, van der Valk CM, Meijer G, Dalmeijer RAJ, de Groot K, Layrolle P. Osteointegration of biomimetic apatite coating applied onto dense and porous metal implants in femurs of goats. J Biomed Mater Res Part B, 2003, 67(1): 655-665.

[4] Wang XX, Hayakawa S, Tsuru K, Osaka1 A. A comparative study of in vitro apatite deposition on heat-, $\mathrm{H}_{2} \mathrm{O}_{2-}$, and $\mathrm{NaOH}$-treated titanium surfaces. J Biomed Mater Res, 2001, 54(2): 172-178.

[5] Wen HB, Wolke JGC, de Wijn JR, Liu Q, Cui FZ, de Groot K. Fast precipitation of calcium phosphate layers on titanium induced by simple chemical treatments. Biomaterials, 1997, 18: 1471-1478.

[6] JCPDS International Center for Diffraction Data, Powder Diffraction File, Swarthmore, PA, 1980.

[7] Wen HB, de Wijn JR, Cui FZ, de Groot K. Preparation of bioactive Ti6Al4V surfaces by a simple method. Biomaterials, 1998, 19: 215-221.

[8] Healy KE, Ducheyne P. The mechanisms of passive dissolution of titanium in a model physiological environment. J Biomed Mater Res, 1992, 26: 319-338.

[9] Healy KE, Ducheyne P. Hydration and preferential molecular adsorption on titanium in vitro. Biomaterials, 1992, 13(8): 553-561. 